\title{
CORRESPONDENCE
}

\section{The Prevalence of Gestational Diabetes}

A Population-Based Analysis of a Nationwide Screening Program

by Dr. phil. Hanne Melchior, Diana Kurch-Bek, Dr. med. Monika Mund in issue $24 / 2017$

\section{Helpful or Harmful?}

I would like to thank the authors for this very important study (1). Nevertheless, I see the results less positively than the authors, as the screening guidelines are not followed in about one-third of participants who need further testing. Of the women who were given the pre-test, $12.7 \%$ also underwent the diagnostic test (i.e., oGTT) in case of a result defined as pathological - according to the guideline of the screening program. Yet $4.8 \%$ only received the diagnostic test. Thus, one-third of women needing further testing do not receive the care defined in the guideline $(4.8 \%$ of $17.5 \%$ woman with further testing). But screenings are designed in a way that a defined optimum between harm and benefit will be achieved when following a predetermined diagnostic test. In this case, stepwise testing is required: first, the pre-test; then, if the results are abnormal, the diagnostic test. Not adhering to this process, and only performing the diagnostic test, can lead to incalculable shifts between benefit and harm - and this happened for almost one-third of pregnant women who were defined as having gestational diabetes.

Now, it could be argued that it does not matter anyway as the screening is not based on evidence from clinical studies (2) — which is always expected for screenings today; rather, all knowledge about thresholds of test-values or benefits stem from only five, mostly very small therapy-studies. Thus, the question about the thresholds, and therefore who should or should not be treated, cannot be answered based on screening-studies. Nevertheless, mistakes that have already been made, and that are potentially dangerous for pregnant women, should not be further complimented by arbitrary performing. This is especially true for a screening for which the benefit, which cannot be clearly put into numbers, but-unlike in women with manifest diabetes - has to be extremely small $(3,4)$.

DOl: 10.3238/arztebl.2017.0689a

\section{REFERENCES}

1. Melchior H, Kurch-Bek D, Mund M: The prevalence of gestational diabetesa population-based analysis of a nationwide screening program. Dtsch Arztebl Int 2017; 114: 412-8.

2. Koch $K$, Horvarth $K$, Siebenhfer A: Was ist bei Behandlung von Schwangeren mit Gestationsdiabetes zu erwarten? Systematische Literaturanalyse und Metaanalyse zu Therapiestudien aus 4 Jahrzehnten. Z Allg Med 2010; 86: 278-89.

3. Abholz H H: Screening auf Gestationsdiabetes - Warum reichen Studien zum Behandlungsnutzen nicht für die Einführung eines Screenings aus? Z Allg Med 2010; 86: 290-5

4. Cundy T, Holt RIG: Gestational diabetes: paradigm lost? Diabetic Med 2017; 34: $8-13$.

\section{Prof. (emer) Dr. med. Heinz-Harald Abholz}

Institute of General Practice, Universität Düsseldorf, Germany

abholz@med.uni-duesseldorf.de

\section{Statistics Visualization not Very Successful}

In their article, Melchior et al. attempt to convey different percentages graphically using a modified pie chart (1).

The study cohort comprised 567191 pregnant women. In the outer part of the pie diagram, the proportion of pregnant women is shown with respect to screening implementation. For example, only the pre-test was used in 63.3\% (approximately 359 032) of the pregnant women. The prevalence of gestational diabetes (GDM) was 13.2\% (approximately 74869 pregnant women). Of these $13.2 \%, 4.4 \%$ - that is, around 24956 pregnant women (and not $4.4 \%$ of $13.2 \%$, which would be 3294 pregnant women) - fell into the "only pre-test" category. This means that approximately $33 \%$ of all GDM pregnant women were examined only with the pre-test. Thus, the pie slice should have been 120 degrees, since in pie charts, the sum of all pie slices must be 360 degrees. Instead, the authors used an angle of 15.8 degrees (15.8/360 degrees $=4.4 \%$ ).

Even if the authors intended to deviate from the usual pie charts, it remains difficult due to the physiology of the human eye: 1) to correctly recognize angles at all, and 2) to correctly recognize angles of pie slices that are not contiguously distributed over 360 degrees. If the authors think this is irrelevant as the percentages are given over the pie slices anyway, the question then arises about the value of the diagram. In general, pie charts are viewed critically. Indeed, Cleveland and McGill pointed out already in 1985 that pie charts, which require angle degrees to be recognized by eye, are interpreted less exactly than bar charts, which require only heights or lengths to be determined by eye (2).

DOI: 10.3238/arztebl.2017.0689b

\section{REFERENCES}

1. Melchior H, Kurch-Bek D, Mund M: The prevalence of gestational diabetes-a population-based analysis of a nationwide screening program. Dtsch Arztebl Int 2017; 114: 412-8.

2. Cleveland WS, McGill R: Graphical perception and graphical methods for analyzing scientific data. Science 1985; 229: 828-33.

\section{Prof. Dr. med. Andreas Stang, MPH}

c/o Institute of Medical Informatics, Biometry, and Epidemiology (IMIBE)

Center of Clinical Epidemiology (CCE)

University Hospital of Essen, Germany

andreas.stang@uk-essen.de

\section{Conflict of interest statement}

The author declares that no conflict of interest exists.

\section{Deeper Analysis Desirable}

In their article, Melchior et al. present prevalence estimates of gestational diabetes of all statutory insured pregnant women from 2014 to 2015 with a total prevalence of $13.2 \%$ (1). The authors contrast their findings with our study analyzing incident cases of gestational diabetes among women insured at a statutory health insurance (AOK Berlin) during 2005 to 2007. The incidence of gestational diabetes was $16 \%(2)$.

The authors attribute the differences to a more stringent definition of our study population. Indeed, we used much stricter exclusion criteria, such as exclusion of multiple pregnancies, unclear diagnosis of diabetes, and multiple reimbursement. The aim of 
our study was not to determine a population-representative prevalence, but to provide a comparative analysis of the gestational diabetes incidence between women of Turkish and German origin. For this purpose, a data set for the period from 2005 to 2007 was used with pregnant women who were insured with AOK Berlin throughout the year, from which we identified all women of Turkish origin using a name-based algorithm (3), and randomly selected women of German origin as a comparison group. One reason for the higher incidence in our study can therefore be the selective composition of the study population. We were able to show that Turkish origin is an independent risk factor for gestational diabetes, especially for young women of Turkish origin with obesity (2). However, an estimation of the gestational diabetes rate in the whole population is only possible to a very limited extent.

In contrast, Melchior et al. use nationwide reimbursement data and can thus provide important representative results on the frequency of gestational diabetes in Germany. In the future, deeper analyses regarding risk differences in gestational diabetes and birth outcomes according to social determinants, such as migration background, would be desirable in order to identify possible risk groups and deficits in care of pregnant women. DOI: $10.3238 / a r z t e b l .2017 .0689 c$

\section{REFERENCES}

1. Melchior H, Kurch-Bek D, Mund M: The prevalence of gestational diabetes-a population-based analysis of a nationwide screening program. Dtsch Arztebl Int 2017; 114: 412-8.

2. Reeske A, Zeeb H, Razum 0, Spallek J: Differences in the Incidence of gestational diabetes between women of Turkish and German origin: An Analysis of Health Insurance Data From a Statutory Health Insurance in Berlin, Germany (AOK), 2005-2007. Geburtshilfe Frauenheilkd 2012; 72: 305-10.

3. Razum 0, Zeeb H, Akgün S: How useful is a name-based algorithm in health research among Turkish migrants in Germany? Trop Med Int Health 2001; 6: 654-61.

\section{Dr. PH Anna Reeske}

Federal Institute for Occupational Safety and Health (BAuA), Dortmund, Germany Anna_Reeske@web.de

\section{Prof. Dr. PH Jacob Spallek}

Institut für Gesundheit, FG Gesundheitswissenschaften,

Brandenburg University of Technology Cottbus-Senftenberg, Senftenberg, Germany

\section{Conflict of interest statement}

The authors declare that no conflict of interest exists.

\section{Not a Population-Based Survey}

Melchior et al. (1) calculate a prevalence of gestational diabetes (GDM) in Germany of $13.2 \%$ from statutory health insurance billing data. The numbers presented are not plausible. Among other things, $1.3 \%$ of the pre-existing cases of diabetes were incorrectly included in the GDM prevalence, so that a maximum of $11.9 \%$ should have been given. According to the quality assurance report on obstetrics 2015 (2), the GDM prevalence in Germany was $4.95 \%$. Also, the authors provide no explanation as to why $1.8 \%$ of the GDM-coded cases were for pregnant women who had not been tested. The pre-test alone indicated a GDM prevalence of $4.4 \%$. It is clinically impossible that a blood glucose $>200 \mathrm{mg} / \mathrm{dL}(11.1 \mathrm{mmol} / \mathrm{L})$ should have been achieved in $4.4 \%$ of all pregnant women in the pre-test-which would have been required to make a GDM diagnosis without oGTT (3).

On the basis of 573000 pregnant women, the authors calculate 12340 cases with overt diabetes. In contrast, the perinatal statistics 2015 of the Institute for Quality Assurance and Transparency in Healthcare (IQTIG) show only 6579 cases in 715000 pregnant women (2). It is impossible that every second case of a pre-existing or newly diagnosed overt diabetes was not documented in the maternal health passport or was overlooked at birth.

The authors failed to use the proportion of insulin treatments as a control or to perform systematic random checks. From our point of view, Melchior et al. either studied an unrepresentative cohort, or have described massive errors in the coding and billing of GDM in Germany that lead to false prevalence figures. In no way can this be considered to be a population-based survey.

DOI: 10.3238/arztebl.2017.0690a

\section{REFERENCES}

1. Melchior H, Kurch-Bek D, Mund M: The prevalence of gestational diabetes-a population-based analysis of a nationwide screening program. Dtsch Arztebl Int 2017; 114: 412-8.

2. Institut für Qualitätssicherung und Transparenz im Gesundheitswesen: Bundesauswertung zum Erfassungsjahr 2015, Geburtshilfe, Qualitätsindikatoren. www.iqtig.org/downloads/ergebnisse/qidb/2015/2016-05-25/QIDB_2015 INDIREKT_PDF/QIDB_2015_indirekte_Leistungsbereiche/BuAw_2015_INDIREKT/ bu_Gesamt_16N1-GEBH_2015.pdf (last accessed on 27 December 2016).

3. Kleinwechter $H$, Schäfer-Graf U, Bührer C, et al.: Gestationsdiabetes mellitus (GDM). Evidenzbasierte Leitlinie zu Diagnostik, Therapie und Nachsorge der Deutschen Diabetes-Gesellschaft und der Deutschen Gesellschaft für Gynäkologie und Geburtshilfe (DGGG). Diabetologie 2011; 6: 290-328.

\section{Dr. med. Helmut Kleinwechter}

Kiel, Germany (DDG-recognized diabetologist)

hkleinwechter@gmail.com

Prof. Dr. med. Werner A. Scherbaum

Düsseldorf, Germany

Prof. Dr. med. Ute Schäfer-Graf

Berlin, Germany

Dr. med. Norbert Demandt, Dr. med. Andreas Nolte

Kiel, Germany

\section{Conflict of interest statement}

Prof. Scherbaum has received speaking honoraria for scientific conferences from medupdate.

Prof. Schäfer-Graf has received honoraria for authorship related to the topic from Elsevier, reimbursement for conference fees and travel expenses from Novo Nordisk, and honoraria from scientific conference preparation from Novo Nordisk, Berlin Chemie, and Sanofi.

Dr. Kleinwechter, Dr. Demandt, and Dr. Nolte declare that no conflict of interest exists.

\section{In Reply:}

We would like to thank all authors of the correspondences for their interest in, and feedback on our article (1).

In response to Prof. Abholz: As shown in Figure 2, 63.3\% of the pregnant women exclusively received the pre-test. For $12.7 \%$, the diagnostic test was also performed. Therefore, $76 \%$ of the pregnant women were tested as defined in the Federal Joint Committee (G-BA) Maternity Guidelines (2); in our opinion, this does not reflect random implementation. Screening is an optional offer, according to the maternity guidelines, which is accompanied by a clear presentation of its advantages and disadvantages (see Annex 6 of the maternity guidelines [2]). It cannot be argued that pregnant women who forego the offered screening have received "substandard care". Only $4.8 \%$ of the cohort received a diagnostic test without a documented pretest; the reasons for this approach cannot be derived from the billing data.

The reason why screening was introduced by the Federal Joint Committee (G-BA) was not the topic of the present analysis; as 
mentioned in our introduction, the decision was based on the expert report from the Institute for Quality and Efficiency in Health Care (IQWiG) (3).

In response to Prof. Stang: We had numerous discussions about how to present the relative frequencies in a meaningful and understandable manner. The representation of a circle diagram with an outer ring (applied test method) and an inner ring (the resulting diagnosis of GDM or not) seemed to us to be logical. The reference size for both rings is the entire study cohort $(\mathrm{N}=567$ 191). If one sets the number of pregnant women with GDM and „only pre-test“ $(\mathrm{N}=25019)$ in relation to the total study cohort, $4.4 \%$ is obtained. If the inner ring were to represent only the pregnant women with GDM, the proportion would be $33 \%$ as described by the author. We deliberately chose to show the two subpopulations with respect to the same population (that is, the entire study cohort), since this seemed to us to be the most comprehensible representation (1). We will, however, take into account the valuable suggestion for future work and think critically about representations using circle diagrams.

In response to Dr. Reeske and Prof. Spallek: We share the opinion of the authors. Further studies on how to treat GDM, the treatment outcome, and the predictive factors for development of GDM are necessary, especially in light of indications of an increased prevalence, as can be derived from our analyses.

In response to Dr. Kleinwechter et al.: As described in the text and in Figure 1, women with pre-existing diabetes were not included in the prevalence calculation but rather were excluded from the population as a whole $(\mathrm{N}=5363)$. Manifest diabetes was coded for the first time during the studied pregnancy for $1 \%$ of women $(\mathrm{N}=5956)$. If these cases are subtracted from the total prevalence, the GDM prevalence is $12.2 \%$, as indicated in the text. We chose not to provide detailed explanations about why GDM diagnoses were made without testing $(1.8 \%)$ or were made based only on the pre-test $(4.4 \%)$. These may be women who were diagnosed based on tests other than those prescribed by the maternity guidelines or who were tested but not billed within the nationwide panel doctor billing set, for instance, if testing occurred outside the recommended test period (4). However, based on the data available to us, we can only speculate about these reasons.

Using insulin treatments as an additional control, as requested by the authors, is not possible based on the available data set; to our knowledge, however, such a validation would also likely be distorted due to the known heterogeneous procedures of insulin treatment (4).

Since the selected population equals approximately $80 \%$ of the current births over one year, we assume that the cohort is representative. The limitations of the billing data analyses that should be considered are given in detail in the text. The resulting GDM prevalence corresponds to the current estimates for Europe. DOI: 10.3238/arztebl.2017.0690b

\section{REFERENCES}

1. Melchior H, Kurch-Bek D, Mund M: The prevalence of gestational diabetes-a population-based analysis of a nationwide screening program. Dtsch Arztebl Int 2017; 114: 412-8.

2. Gemeinsamer Bundesausschuss: Richtlinien über die ärztliche Betreuung während der Schwangerschaft und nach der Entbindung („Mutterschafts-Richtlinien“). www.g-ba.de/downloads/62-492-1223/Mu-RL_2016-04-21_2016-07-20.pdf (last accessed on 16 August 2017).

3. Institut für Qualität und Wirtschaftlichkeit im Gesundheitswesen (IQWIG): Screening auf Gestationsdiabetes - Abschlussbericht. www.iqwig.de/download/ S07-01_Abschlussbericht_Screening_auf_Gestationsdiabetes.pdf (last accessed on 16 August 2017).

4. Adamczewski H, Weber F, Faber-Heinemann G, Heinemann L, Kaltheuner M: Einfluss der Gestationsdiabetes-Leitlinie der DDG auf die Versorgungsrealität: Analysen des Register GestDiab. Diabetol Stoffwechs 2016; 11: 341-9.

On behalf of the authors:

Dr. phil. Hanne Melchior

Kassenärztliche Bundesvereinigung

Dezernat 7 - Sektorenübergreifende Qualitäts- und Versorgungskonzepte

Abteilung Indikationsbezogene Versorgungskonzepte, Berlin

hmelchior@kbv.de

\section{Conflict of interest statemen}

The author declares that no conflict of interest exists. 